\title{
Zero-lag long-range synchronization via hippocampal dynamical relaying
}

\author{
Leonardo L Gollo ${ }^{1 *}$, Claudio R Mirasso', Mercedes Atienza², Maité Crespo-Garcia², José L Cantero² \\ From Nineteenth Annual Computational Neuroscience Meeting: CNS*2010 \\ San Antonio, TX, USA. 24-30 July 2010
}

Oscillations of cortical areas in gamma frequencies has been extensively studied, however, distant cortical areas are able to synchronize in other ranges besides the gamma band. Local field potentials recorded from the frontal (F) and visual (V) cortical areas of a rat performing exploratory motor behavior (active state) and motor quiescent (passive state) present distinct features concerning to the zero-lag synchronization of the two cortical regions.
In this work, we study the occurrence of zero-lag synchronization of distant cortical areas in the theta band mediated by the hippocampus $(\mathrm{H})$. We propose to model the different behavioral states (passive and active) with the dynamical relaying mechanism [1-3]. The model shows good agreement with the experiment as displayed in Fig. 1, for the density of peaks obtained from the sliding window of the filtered average membrane potential cross-correlograms.
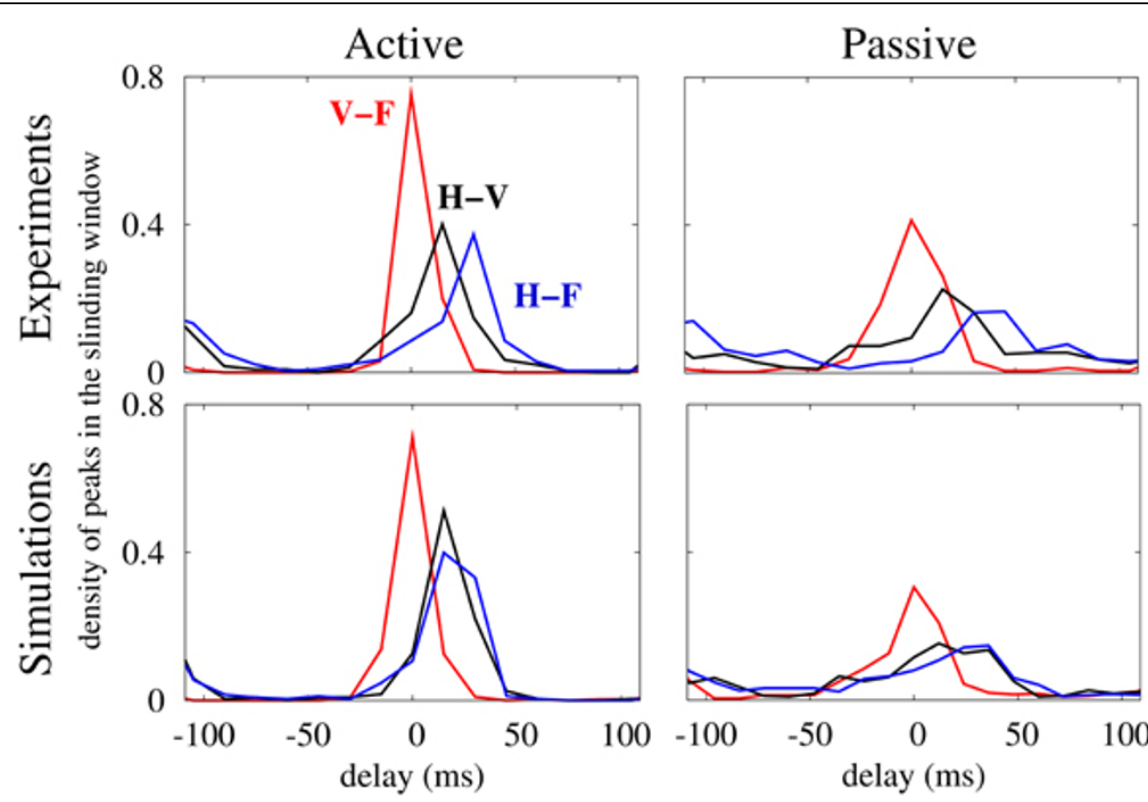

Figure 1 Comparison between numerical simulations and experimental data for both active and passive states. The curves represent the normalized histogram of the density of peaks in each of the cross-correlogram sliding window (from -300 to 300 ms) of 1 minute long of filtered time series.

\footnotetext{
* Correspondence: leonardo@ifisc.uib-csic.es

${ }^{1}$ IFISC (CSIC-UIB), Instituto de Física Interdisciplinary Sistemas Complejos,

Campus Universitat des Illes Balears, E-07122 Palma de Mallorca, Spain
} 


\section{Conclusions}

During the active state visual and frontal areas activate more coherently when compared to the passive state, as can be seen from a higher peak in the cross-correlogram shown in figure 1 . The theta band synchronization of neuronal activity in the frontal and visual cortical regions can be explained by the dynamical relaying phenomenon in which the hippocampus is assumed to play the role of the mediating element.

\section{Author details}

${ }^{1}$ IFISC (CSIC-UIB), Instituto de Física Interdisciplinary Sistemas Complejos, Campus Universitat des Illes Balears, E-07122 Palma de Mallorca, Spain.

${ }^{2}$ Laboratory of Functional Neuroscience, Network for Biomedical Research on Neurodegenerative Diseases (CIBERNED), University Pablo de Olavide, Seville, Spain.

Published: 20 July 2010

\section{References}

1. Fischer I, Vicente R, Buldu JM, Peil M, Mirasso CR, Torrent MC, GarciaOjalvo J: Zero-lag long-range synchronization via dynamical relaying. Physical Review Letters 2006, 97:123902.

2. Vicente R, Gollo LL, Mirasso CR, Fischer I, Pipa G: Dynamical relaying can yield zero time lag neuronal synchrony despite long conduction delays. Proc Natl Acad Sci U S A 2008, 105:17157-17162.

3. Gollo LL, Mirasso CR, Villa AE: Dynamic control for synchronization of separated cortical areas through thalamic relay. Neurolmage.

Cite this article as: Gollo et al:: Zero-lag long-range synchronization via hippocampal dynamical relaying. BMC Neuroscience 2010 11(Suppl 1):P17.

\section{Submit your next manuscript to BioMed Central} and take full advantage of:

- Convenient online submission

- Thorough peer review

- No space constraints or color figure charges

- Immediate publication on acceptance

- Inclusion in PubMed, CAS, Scopus and Google Scholar

- Research which is freely available for redistribution

Submit your manuscript at www.biomedcentral.com/submit 